\title{
Partnership Selection of Agile Virtual Enterprise Based on Grey Ant Colony Algorithm
}

\author{
Y.D. Fang ${ }^{1}$, L.H. Du ${ }^{2}$, H. Chen ${ }^{1}$, B. Sun ${ }^{1}$, and Y.L. He ${ }^{3}$ \\ ${ }^{1}$ Jin Hua North Road 4\#, The Institute of Mechanical and Electrical Engineer, Xi'an \\ Technological University, Xi'an, Shaan Xi, P.R.C \\ tomfangok@126.com, Chenhua126@163.com, sunbomm@163.com \\ ${ }^{2}$ Cui Hua South Road 44\#, School of Information,Xi'an University of Finance and Economics, \\ Xi'an, Shaan Xi, P.R.C \\ dulh06@126.com \\ ${ }^{3}$ You Yi western Road 127 \#, The Key Laboratory of Contemporary Design and Integrated \\ Manufacturing Technology, Northwestern Polytechnic University, Xi'an, Shaan Xi, P.R.C \\ heyl@nwpu.edu.cn
}

\begin{abstract}
The paper analyzes the art of partner selection, and enumerates the advantage of partnership selection based on grey relation theory and ant colony algorithm. Furthermore, evaluation framework of agile virtual enterprise (AVE) partner pre-election is analyzed and designed based on the characteristics of AVE. According to grey relation theory, considerable candidate enterprises are selected to reduce the size of problem. Lastly, cooperative enterprise selecting path is decided by making use of ant colony algorithm in terms of transportation cost.
\end{abstract}

Keywords: partner selection, grey relation theory, ant colony algorithm, agile virtual enterprise.

\section{Introduction}

Agile Virtual Enterprise (AVE) is a dynamic organization on the web environment, which is composed of a number of independent enterprises connected by information technology based on various hierarchy resources integration and sharing [1]. It's important to get the optimum cooperative enterprise scheme by analyzing, arranging and evaluating character information of candidate enterprise for AVE. At present, partner selection of the AVE always utilizes integer programming, fuzzy evaluation, multiple objectives programming, grey relation theory and so on. For example, P.Gutpa [2] introduces partner selection method in the distributed manufacturing environment according to evaluation of product manufacturing capability; Kasilingam [3] discusses partner selection problem in terms of cost by mixed integer programming method; Hinkle [4] selects partner according to cluster analysis; Siying [5] discusses partner selection problem by neural networks method; N.Q. Wu [6] puts forward partner selection algorithm based on graph method; P.J.Ma [7] introduces partner selection by fuzzy analysis hierarchy process. These methods don't consider scheduling relationship among manufacturing tasks, and it's difficult to evaluate various indices synthetically by the methods. 
Grey relation analysis belongs to grey system theory put forward by Professor Deng Ju-long [8] in 1982, and it mainly researches quantification analysis problem of system state development. In grey relation theory, the geometry curve constructed by several stat. data is more similar, the relation degree is bigger. The relation sequence reflects approximate sequence of each project to objective project, and the project of maximal grey relation degree is best one. Ant colony algorithm [9] has character of positive feedback, distributing compute and heuristic search, and it is successfully applied in NP-hard problem (such as, traveling salesman problem (TSP), scheduling problem and job-shop problem). To typical TSP problem about Oliver30、Eil50 and Ei175, ant colony algorithm, genetic algorithm and simulated annealing algorithm are compared in optimization quality and convergence speed by simulation analysis in reference [10], and the experiment result shows that ant colony algorithm is most satisfied. Partner selection of AVE is directed graph in the nature, which is similar to TSP. The paper hence adopts nature heuristic approach, which is ant colony algorithm, to resolve partner selection of AVE driven by working procedure. What's more, grey relation theory is applied into the problem at each task vertex to reduce problem resolved space.

\section{Grey Relation Approaches to AVE Partner Pre-election}

\subsection{Evaluation Framework of AVE Partner Pre-election}

AVE partner is mainly pre-elected from time, cost, quality and service. The preselection evaluating index of AVE partner is made up of cost evaluating index, history evaluating index, time evaluating index and general evaluating index [11], and the evaluation system is shown as Fig.1

- Cost evaluating index $\left(\mathrm{L}_{1}\right)$

The cost index information includes biding price $\left(\mathrm{L}_{11}\right)$ and transporting fee $\left(\mathrm{L}_{12}\right)$. $\mathrm{L}_{11}$ indicates that candidate enterprise put forward processing fee to finish assigned manufacturing task; $\mathrm{L}_{12}$ is transporting expenses from candidate enterprise to core enterprise.

- History evaluating index $\left(\mathrm{L}_{2}\right)$

History evaluating index is made up of credit for collaboration $\left(\mathrm{L}_{21}\right)$, capability of disposing exception $\left(\mathrm{L}_{22}\right)$, quality of after service $\left(\mathrm{L}_{23}\right)$ and production quality grade $\left(\mathrm{L}_{24}\right)$. The digital rule of above index is: AAAAA(5)、AAAA(4)、AAA(3)、AA(2)、A(1).

- Time evaluating index $\left(\mathrm{L}_{3}\right)$

Time evaluating index is made up of production completion time $\left(\mathrm{L}_{31}\right)$ and project postponing dateline $\left(\mathrm{L}_{32}\right)$.

- General evaluating index $\left(\mathrm{L}_{4}\right)$

General evaluating index estimates candidate enterprises from its scope $\left(\mathrm{L}_{41}\right)$, enterprise important degree $\left(\mathrm{L}_{42}\right)$ and equipment capability $\left(\mathrm{L}_{43}\right)$. Moreover, the numeralization rule of general evaluating index includes: enterprise important level is divided into monopolization status (5), domination status (4), leading status (3), participation status (2), and obedience status (1); Equipment capability is made up of international leading level (5), international general level (4), internal leading level (3), internal general level (2), and behindhand status (1). 


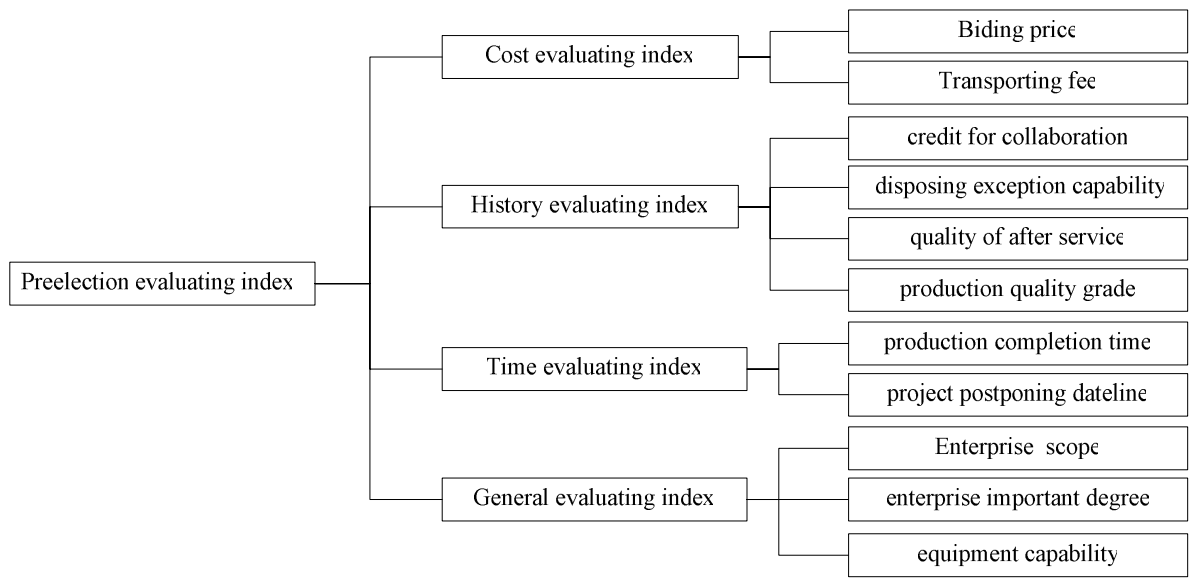

Fig. 1. Evaluation index system of AVE partner pre-election

\subsection{Instance Analysis of Partner Selection Based on Grey Relation}

Optimum set (reference sequence) is firstly determined in partner grey selection [12]. Cooperative manufacturing partner is filtered by acquiring grey relation coefficient of three hierarchies according to pre-election evaluating index system discussed in Section 2.1. The paper discusses AVE partner pre-election problem by giving an example of working procedure about semi-finishing turning flank groove for one aeroplane engineer front casket. In terms of final grey relation coefficient, five enterprises to be satisfied are chosen from ten candidate enterprises, and the detail information of each candidate enterprises is shown as Table 1.

According to the principle of the lowest cost, shortest manufacturing times, production excellent quality and most quick response speed, the optimum set is: $\mathrm{T}^{*}=$ $\left\{\mathrm{T}^{* 1}, \mathrm{~T}^{*}, \mathrm{~T}^{*}, \mathrm{~T}^{* 4}\right\}=\{\{1.8,0.23\},\{5,5,5,5\},\{13,2\},\{4,5\}\}$, and the precedence arrangement sequence of each evaluating index is shown as: $\mathrm{L}_{11}>\mathrm{L}_{12}$; $\mathrm{L}_{21}>\mathrm{L}_{24}>\mathrm{L}_{22}>\mathrm{L}_{23} ; \mathrm{L}_{31}>\mathrm{L}_{32} ; \mathrm{L}_{43}>\mathrm{L}_{41}>\mathrm{L}_{42} ; \mathrm{L}_{1}>\mathrm{L}_{3}>\mathrm{L}_{2}>\mathrm{L}_{4}$. The first and second hierarchy evaluating index judgment matrixes are:

$$
\begin{aligned}
E_{1}^{2} & =\left[\begin{array}{ll}
1 & 4 \\
1 / 4 & 1
\end{array}\right], \quad E_{2}^{2}=\left[\begin{array}{llll}
1 & 5 & 7 & 3 \\
1 / 5 & 1 & 3 & 1 / 3 \\
1 / 7 & 1 / 3 & 1 & 1 / 5 \\
1 / 3 & 3 & 5 & 1
\end{array}\right] \quad E_{3}^{2}=\left[\begin{array}{ll}
1 & 4 \\
1 / 4 & 1
\end{array}\right] \quad E_{4}^{2}=\left[\begin{array}{lll}
1 & 5 & 1 / 5 \\
1 / 5 & 1 & 1 / 9 \\
5 & 9 & 1
\end{array}\right] \\
E^{1} & =\left[\begin{array}{llll}
1 & 5 & 3 & 7 \\
1 / 5 & 1 & 1 / 3 & 3 \\
1 / 3 & 3 & 1 & 5 \\
1 / 7 & 1 / 3 & 1 / 5 & 1
\end{array}\right] .
\end{aligned}
$$

We can get weight vector of multi-hierarchy judgment matrixes by data pretreatment and plus multiply disposal, vector: $W_{1}^{2}=\{0.75,0.25\} ; W_{2}^{2}=\{0.74,0.21$, 
Table 1. Detail information table of candidate enterprise

\begin{tabular}{llllllllllll}
\hline Candidate Set & $\mathrm{L}_{11}$ & $\mathrm{~L}_{12}$ & $\mathrm{~L}_{21}$ & $\mathrm{~L}_{22}$ & $\mathrm{~L}_{23}$ & $\mathrm{~L}_{24}$ & $\mathrm{~L}_{31}$ & $\mathrm{~L}_{32}$ & $\mathrm{~L}_{41}$ & $\mathrm{~L}_{42}$ & $\mathrm{~L}_{43}$ \\
\hline Enterprise I & 2.2 & 0.52 & 3 & 4 & 5 & 2 & 16 & 3 & 0.02 & 4 & 4 \\
Enterprise II & 2.6 & 0.34 & 5 & 5 & 2 & 3 & 13 & 5 & 0.8 & 3 & 2 \\
Enterprise III & 3.1 & 0.23 & 2 & 3 & 4 & 2 & 22 & 4 & 0.12 & 2 & 3 \\
Enterprise IV & 2.1 & 0.45 & 1 & 1 & 3 & 5 & 24 & 6 & 1.58 & 2 & 1 \\
Enterprise V & 1.8 & 0.49 & 4 & 4 & 5 & 4 & 18 & 3 & 0.78 & 4 & 5 \\
Enterprise VI & 2.8 & 0.78 & 5 & 5 & 1 & 3 & 17 & 7 & 2.12 & 1 & 2 \\
Enterprise VII & 2.9 & 0.66 & 2 & 3 & 3 & 2 & 21 & 3 & 0.09 & 3 & 3 \\
Enterprise VIII & 1.9 & 0.32 & 4 & 2 & 4 & 5 & 26 & 5 & 0.56 & 4 & 4 \\
Enterprise IX & 2.7 & 0.41 & 5 & 4 & 2 & 4 & 20 & 3 & 1.92 & 2 & 5 \\
Enterprise X & 2.5 & 0.72 & 1 & 1 & 3 & 3 & 19 & 2 & 0.99 & 4 & 1 \\
\hline
\end{tabular}

$0.08,0.43\} ; W_{3}^{2}=\{0.75,0.25\} ; W_{4}^{2}=\{0.28,0.06,0.67\} ; W^{1}=\{0.51,0.14,0.30,0.05\}$. There need to pretreat the data of assessment index, before grey relation coefficient is determined. What's more, the rule of treatment for cost type index is T*(i)/T (i), and the first grade difference matrix is:

$\mathrm{P}=\left\{\mathrm{P}_{1}, \mathrm{P} 2, \mathrm{P} 3, \mathrm{P}_{4}\right\}=$

$\left[\begin{array}{llllllll}0.08 & 0.14 \vdots 0.14 & 0.08 & 0.00 & 0.20 \vdots 0.07 & 0.08 \vdots 0.02 & 0.00 & 0.06 \\ 0.14 & 0.08 \vdots 0.00 & 0.00 & 0.19 & 0.13 \vdots 0.00 & 0.14 \vdots 0.14 & 0.09 & 0.19 \\ 0.19 & 0.00 \vdots 0.22 & 0.14 & 0.07 & 0.20 \vdots 0.14 & 0.12 \vdots 0.22 & 0.18 & 0.12 \\ 0.06 & 0.12 \vdots 0.28 & 0.28 & 0.12 & 0.00 \vdots 0.16 & 0.15 \vdots 0.06 & 0.18 & 0.25 \\ 0.00 & 0.13 \vdots 0.08 & 0.08 & 0.00 & 0.07 \vdots 0.10 & 0.08 \vdots 0.15 & 0.00 & 0.00 \\ 0.17 & 0.18 \vdots 0.00 & 0.00 & 0.24 & 0.13 \vdots 0.09 & 0.16 \vdots 0.00 & 0.27 & 0.19 \\ 0.18 & 0.16 \vdots 0.22 & 0.14 & 0.12 & 0.20 \vdots 0.14 & 0.07 \vdots 0.22 & 0.09 & 0.12 \\ 0.02 & 0.07 \vdots 0.08 & 0.22 & 0.07 & 0.00 \vdots 0.18 & 0.14 \vdots 0.17 & 0.00 & 0.06 \\ 0.15 & 0.11 \vdots 0.00 & 0.08 & 0.19 & 0.07 \vdots 0.12 & 0.07 \vdots 0.02 & 0.18 & 0.00 \\ 0.13 & 0.17 \vdots 0.28 & 0.28 & 0.12 & 0.13 \vdots 0.11 & 0.00 \vdots 0.12 & 0.00 & 0.25\end{array}\right]$

In terms of reference [13], each grade grey relation space comparing average values are defined as:

$\bar{\Delta}_{1}=\sum_{i=1}^{10} \sum_{j=1}^{2}\left|P_{i j}\right| /(10 \times 2)=0.1 \quad ; \quad \bar{\Delta}_{2}=\sum_{i=1}^{10} \sum_{j=3}^{6}\left|P_{i j}\right| /(10 \times 4)=0.1$

$\bar{\Delta}_{3}=\sum_{i=1}^{10} \sum_{j=7}^{8}\left|P_{i j}\right| /(10 \times 2)=0.1 ; \quad \bar{\Delta}_{4}=\sum_{i=1}^{10} \sum_{j=9}^{11}\left|P_{i j}\right| /(10 \times 3)=0.1$. According to formula of $\Delta \min =\min _{i} \min _{j}\left|P_{i j}\right|, \Delta \max =\max _{i} \max _{j}\left|P_{i j}\right|$, the maximal value and minimal value of first grade evaluating element are: $\Delta \min _{1}=\Delta \min _{2}=\Delta \min _{3}=\Delta \min _{4}=0$, $\Delta \max _{1}=0.19, \Delta \max _{2}=0.28, \Delta \max _{3}=0.18, \Delta \max _{4}=0.25$. The average value proportion coefficient is defined as: $\gamma=\bar{\Delta} / \Delta \max$,thus, $\gamma_{1}=0.53, \gamma_{2}=0.36, \gamma_{3}=0.56, \gamma_{4}=0.4$. According to definition III of reference [10], the 
distinguishing coefficients are respectively: $\sigma_{1}=0.78, \sigma_{2}=0.61, \sigma_{3}=0.81, \sigma_{2}=0.65$. We can get first grade relation matrix by Eq. 1 .

$$
\begin{gathered}
\xi_{i}^{(j)}=\frac{\Delta \min +\sigma \Delta \max }{P_{i j}+\sigma \Delta \max } . \\
\Omega=\left[\begin{array}{lllllllllll}
0.65 & 0.51 \vdots 0.55 & 0.68 & 1.00 & 0.46 \vdots 0.68 & 0.65 \vdots 0.89 & 1.00 & 0.73 \\
0.51 & 0.65 \vdots 1.00 & 1.00 & 0.47 & 0.57 \vdots 1.00 & 0.51 \vdots 0.54 & 0.64 & 0.46 \\
0.44 & 1.00 \vdots 0.44 & 0.55 & 0.71 & 0.46 \vdots 0.51 & 0.55 \vdots 0.42 & 0.47 & 0.58 \\
0.71 & 0.55 \vdots 0.38 & 0.38 & 0.59 & 1.00 \vdots 0.48 & 0.49 \vdots 0.73 & 0.47 & 0.39 \\
1.00 & 0.53 \vdots 0.68 & 0.68 & 1.00 & 0.71 \vdots 0.59 & 0.65 \vdots 0.52 & 1.00 & 1.00 \\
0.47 & 0.45 \vdots 1.00 & 1.00 & 0.42 & 0.57 \vdots 0.62 & 0.48 \vdots 1.00 & 0.38 & 0.46 \\
0.45 & 0.48 \vdots 0.44 & 0.55 & 0.59 & 0.46 \vdots 0.51 & 0.68 \vdots 0.42 & 0.64 & 0.58 \\
0.88 & 0.68 \vdots 0.68 & 0.44 & 0.71 & 1.00 \vdots 0.45 & 0.51 \vdots 0.49 & 1.00 & 0.73 \\
0.50 & 0.57 \vdots 1.00 & 0.68 & 0.47 & 0.71 \vdots 0.55 & 0.68 \vdots 0.89 & 0.47 & 1.00 \\
0.53 & 0.47 \vdots 0.38 & 0.38 & 0.59 & 0.57 \vdots 0.57 & 1.00 \vdots 0.58 & 1.00 & 0.39
\end{array}\right]
\end{gathered}
$$

On the basis of multi-hierarchy grey relation selection model [15], the multi-hierarchy grey relation coefficient for AVE partner selection is:

$$
C=W_{i} \times \Omega_{i}=\sum_{i=1}^{4} W^{1}(i) \cdot W_{2}^{i} \cdot \Omega_{i}=\{0.67,0.74,0.57,0.63,0.82,0.61,0.52,0.75,0.66,0.58\} .
$$

For the manufacturing task about turning flank groove of one aeroplane engineer front casket, the candidate enterprises pre-elected include: enterprise V, enterprise VIII, enterprise II, enterprise I and enterprise IX.

\section{Application of Ant Colony Algorithm in Selecting AVE Partner}

Considering part manufacturing character, working procedures are arranged for manufacturing chain from the view of the aspect of manufacturing technics, and manufacturing enterprise need to be selected from node of manufacturing chain. Thus, the problem of AVE partner selection is considered as directed graph. The metal cutting working procedure (MCWP) in one aeroplane engineer front casket AVE includes: drilling and boring the hole of plane to be combined (MCWP1), rough milling exterior plane (MCWP2), finish milling the plane to be combined (MCWP3), finish grinding the plane to be combined (MCWP4), boring the plane to be combined (MCWP5), finish milling exterior plane (MCWP6), finish boring radial hole (MCWP7), milling groove of the plane to be combined (MCWP8) and finish turning fore-and-aft groove (MCWP9), and the directed graph of AVE partner selection is shown as Fig.2.

With the increment of working procedure node, the space of problem about partner selection expands rapidly, and it belongs to typical NP-Hard compounding optimization problem. On the basis of AVE partner pre-election in terms of grey relation theory, the paper makes use of ant colony algorithm to search manufacturing path of least cost consumed. 


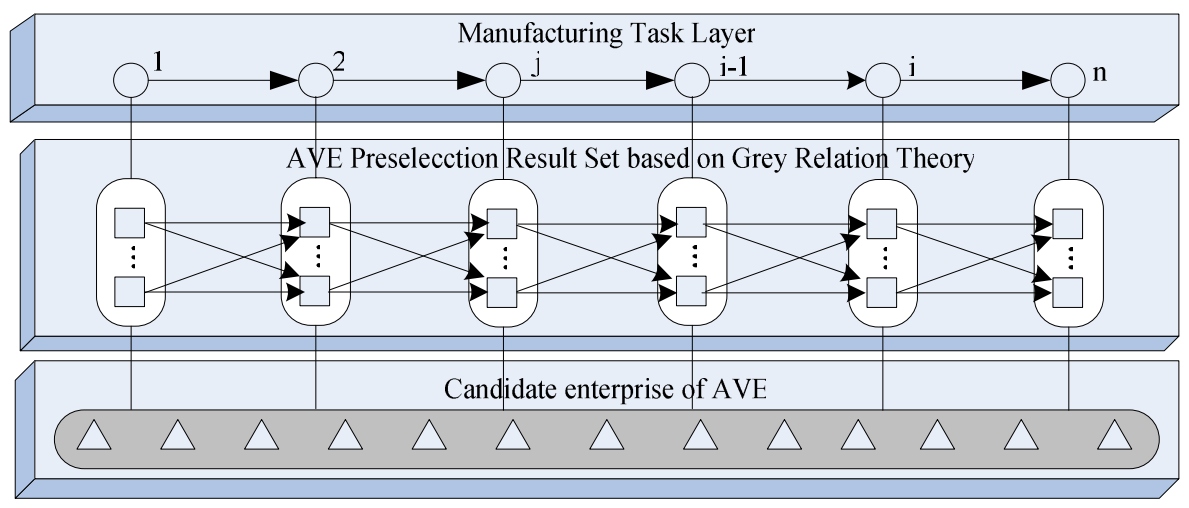

Fig. 2. Directed graph of AVE partner selection

Ant departs from vertex of in-degree zero, and its amount is the same as working procedure. It chooses the next vertex according to information consistency, and the travel is finished at the vertex of out-degree zero. The task of aeroplane engineer front casket includes nine working procedure, and the element of candidate enterprise set $\mathrm{Ai}(\mathrm{i}=1,2 \ldots \mathrm{m})$ from each working procedure should be selected. What's more, the ant chooses the next intention enterprise at the time, and arrives the destination at the $\mathrm{t}+1$ time. All the ants travel IAil steps at the interval of $\mathrm{t}$ and $\mathrm{t}+1$ time, and it is thought that the algorithm finish one times iterative travel. If the algorithm realizes $\mathrm{n}$ times iterative travel, the ant colony algorithm is defined one times cycle, and update formula of information consistence is defined:

$$
\tau_{i j}(t+n)=\rho \times \tau_{i j}(t)+\Delta \tau_{i j} .
$$

Variable $\tau_{i j}(t)$ is denoted information consistency from enterprise $\mathrm{i}$ to enterprise $\mathrm{j}$, and Variable $\rho$ is indicated residual information consistency. When t equals to zero, the original information consistency $\tau_{i j}(0)=0.6 ; \Delta \tau_{i j}$ is increment of information consistency, after the algorithm finishes one travel cycle.

$$
\Delta \tau_{i j}=\sum_{\mathrm{k}=1}^{\mathrm{m}} \Delta \tau_{\mathrm{ij}}^{\mathrm{k}}
$$

$\Delta^{k} \tau_{i j}$ is indicated $\mathrm{k}$ ant leaves information element value from $\mathrm{i}$ enterprise to $\mathrm{j}$ enterprise at the internal of $\mathrm{t}$ and $\mathrm{t}+\mathrm{n}$, and it is calculated:

$$
\Delta^{k} \tau_{i j}=\left\{\begin{array}{ll}
Q / L_{k} & , \text { if } k \text { ant travels from enterprise } i \text { to enterprise } j \\
0 & , \text { otherwise }
\end{array} .\right.
$$

$\mathrm{Q}$ is constant about information consistence that ant leaves, and its value impacts on the convergence speed of ant colony algorithm. The paper discusses how to select appropriate collaborating enterprise for each working procedure by utilizing ant colony algorithm. $\mathrm{P}_{i j}^{k}(t)$ is indicated the probability of $\mathrm{k}$ ant traveling from enterprise $\mathrm{i}$ to enterprise $\mathrm{j}$ : 


$$
\mathrm{P}_{i j}^{k}(t)= \begin{cases}\frac{\left[\tau_{i j}(t)\right]^{\alpha} \cdot\left[\eta_{i j}(t)\right]^{\beta}}{\sum_{A_{j}}\left[\tau_{i j}(t)\right]^{\alpha} \cdot\left[\eta_{i j}(t)\right]^{\beta}} & \text { if } \quad j \in A_{j} \\ 0 & \text { otherwise }\end{cases}
$$

According to definition of arc visibility $\eta_{i j}$ in typical TSP problem for ant colony algorithm, suppose $\eta_{i j}(t)=1 / c_{i j}(t)$. And $c_{i j}(t)$ is denoted the distance between enterprise $\mathrm{i}$ and $\mathrm{j}$. Considering ant colony traveling rule in the process of AVE selection for manufacturing task shown as Fig.2, the transporting cost between vertex of directed graph can be expressed as: $\operatorname{Trans}=\bigcup_{m=1}^{10} T_{m}$, and $T_{I}=\operatorname{Transport}\left(E_{\text {Sponsor }}, E_{j}^{(l)}\right)$, $T_{i}=\operatorname{Transport}\left(E_{j}^{(i)}, E_{k}^{(i+1)}\right), T_{10}=\operatorname{Transport}\left(E_{j}^{(10)}, E_{\text {Sponsor }}\right), i \quad\{1,2, \ldots, 9\}, j \quad\{1,2, \ldots, 5\}$, $k \in\{1,2, \ldots, 5\}$. The transporting cost matrix is acquired by calculating distance among various cities according to china railway passenger transport odograph:

\begin{tabular}{|c|c|c|c|c|c|c|c|c|c|c|c|}
\hline \multirow{5}{*}{$T_{2}=$} & 1489 & 689 & 577 & 511 & 998 & \multirow{5}{*}{$T_{3}=$} & 1489 & 1807 & 547 & 2882 & 2033 \\
\hline & 1807 & 1160 & 1195 & 1206 & 303 & & 689 & 1160 & 1288 & 2042 & 1463 \\
\hline & 2000 & 1159 & 651 & 0 & 1509 & & 577 & 1195 & 1802 & 1493 & 1498 \\
\hline & 547 & 1288 & 1802 & 2453 & 2577 & & 511 & 1206 & 2453 & 842 & 1509 \\
\hline & 2882 & 2042 & 1493 & 842 & 2351 & & 998 & 303 & 2577 & 2351 & 0 \\
\hline \multirow{5}{*}{$T_{4}=$} & 1187 & 577 & 1489 & 511 & 511 & \multirow{5}{*}{$T_{5}=$} & 3099 & 1172 & 1811 & 1182 & 1187 \\
\hline & 1182 & 1195 & 1807 & 1206 & 1206 & & 1424 & 1493 & 3336 & 842 & 2042 \\
\hline & 3099 & 1802 & 547 & 2453 & 2453 & & 0 & 2882 & 741 & 1807 & 1489 \\
\hline & 1172 & 1493 & 2882 & 842 & 842 & & 2000 & 842 & 1159 & 1206 & 511 \\
\hline & 2185 & 1498 & 2033 & 1509 & 1509 & & 2000 & 842 & 1159 & 1206 & 511 \\
\hline \multirow{5}{*}{$T_{6}=$} & 2000 & 2033 & 547 & 2000 & 741 & \multirow{5}{*}{$T_{7}=$} & 676 & 511 & 1206 & 2000 & 842 \\
\hline & 842 & 2351 & 3336 & 842 & 2042 & & 2185 & 998 & 303 & 2033 & 2351 \\
\hline & 1159 & 1463 & 1288 & 1159 & 0 & & 3099 & 2085 & 2277 & 547 & 3336 \\
\hline & 1206 & 303 & 2277 & 1206 & 1160 & & 676 & 511 & 1206 & 2000 & 842 \\
\hline & 511 & 998 & 2085 & 511 & 689 & & 1811 & 689 & 1160 & 741 & 2042 \\
\hline \multirow{5}{*}{$T_{8}=$} & 676 & 3099 & 676 & 1327 & 3099 & \multirow{5}{*}{$T_{9}=$} & 842 & 1159 & 2453 & 1509 & 0 \\
\hline & 511 & 1489 & 511 & 577 & 1489 & & 2882 & 741 & 547 & 2033 & 2000 \\
\hline & 1206 & 2085 & 1206 & 1807 & 2085 & & 842 & 1159 & 2453 & 1509 & 0 \\
\hline & 2000 & 0 & 2000 & 1424 & 0 & & 1493 & 514 & 1802 & 1498 & 651 \\
\hline & 842 & 2882 & 842 & 1493 & 2882 & & 2882 & 741 & 547 & 2033 & 2000 \\
\hline & & 1807 & 2000 & 547 & 288] & $T_{10}=$ & 2882 & 741 & 547 & 2033 & $2000]^{T}$ \\
\hline
\end{tabular}

When one parameter is test, the other parameters are chosen default value to observe influence of the parameter to algorithm, and default value of respective parameter is: $\alpha=1, \beta=2, \rho=0.9, Q=100$. AVE partner selection is calculated 600 


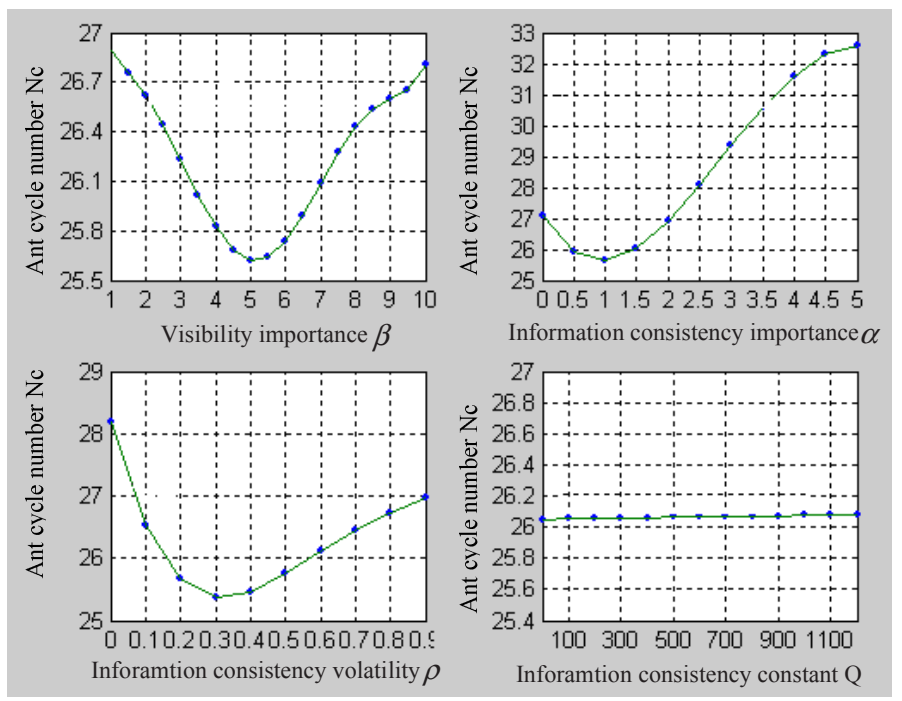

Fig. 3. Ant colony algorithm parameter optimum result analysis based on stat

times for each parameter, and average of experimentation result is computed. The value range of each parameter is: $\alpha \in[0,5], \beta \in[1,10], \rho \in[0,0.9], Q \in[1,1100]$, and stat. analysis of experimentation is shown as Fig.3.

According to simulation result above, the optimization value range of each parameter is: $\beta \in(5-\varepsilon, 5+\varepsilon), \quad \alpha \in(1-\varepsilon, 1+\varepsilon), \quad \rho \in(0.3-\varepsilon, 0.3+\varepsilon), Q \in[100,1100]$. If $\beta$ is too high, ant colony will select candidate enterprise of low transporting cost without considering information consistency. Otherwise, selection probability is influenced by information consistence too much, and it leads to algorithm converge too early. If $\alpha$ is too high, information consistence decides ant colony selection probability, and ant selects the path which the other ant have traveled. Otherwise, ant colony algorithm changes into classic greedy random algorithm. Volatility coefficient $\rho$ reflects memory degree of ant colony for experience. If its value is too low, ant colony algorithm changes into greedy heuristic search, and algorithm cycle times is more. Otherwise, information consistence volatilizes too quickly, and transporting cost among enterprises in large determines selection probability. Information consistence const. $Q$ influences ant colony algorithm search efficiency a little. On the basis of above analysis, the paper gives one group optimization parameter: $\alpha=1, \beta=5, \rho=0.3, Q=800$, and AVE partner selection result is shown as Table 2 .

Table 2. AVE partner selection result based on ant colony algorithm

\begin{tabular}{llllllllllll}
\hline Calculation Num & 1 & 2 & 3 & 4 & 5 & 6 & 7 & 8 & 9 & 10 & Ave \\
\hline Ant cycle Num & 7 & 11 & 20 & 32 & 57 & 5 & 23 & 24 & 11 & 18 & 20.8 \\
Running time( ms) & 125 & 78 & 63 & 78 & 109 & 78 & 78 & 78 & 62 & 94 & 84.3 \\
\hline
\end{tabular}




\section{Conclusions}

The bottleneck of AVE is how to manufacture high quality products at the right time and place by right manufacturing resource. The paper divided partner enterprise of AVE into two stages: In first stage, the partner pre-election of AVE problem is resolved by grey relation theory, ant it reduces problem resolved space and complexity. According to transport cost among candidate enterprises, partner selection is realized by ant colony algorithm on the basis of partner candidate set. Future research is to optimize resource allocation for plant of each AVE partner by grey relation and grey relation theory for the scheduling and dispatch of cooperative manufacturing.

Acknowledgments. The paper is supported by Research Fund of Xi'an Technological University (XAGDXJJ200706), Shaanxi Province Programs for Science and Technology Development (2007K05-11) and National Natural Science Foundation of China (50605051).

\section{References}

1. Yang, S.L., Li, T.F.: Agility evaluation of mass customization production manufacturing. Journal of Material Processing Technology 129, 640-644 (2002)

2. Gupta, P., Rakesh, N.: Flexible Optimization Framework for Partner Selection in Agile Manufacturing. In: Proceedings of the 4th Industrial Engineering Research Conference, pp. 691-700. Nashville, Tennesse (1995)

3. Raja, G.L.: Cheep: Selection of vendors- A Mixed-integer Programming Approach. Computers \& Industrial Engineering 31, 347-351 (1996)

4. Hinkle, C.L., Robinson, P.J., Green, P.E.: Vendor Evaluation Using Cluster Analysis. Journal of Purchasing 29, 49-58 (1996)

5. W, S.Y.: A Supplier-Selecting System Using a Neural Network. In: IEEE International Conference on the Intelligent Processing Systems, vol. 40, pp. 468-471. IEEE Press, New York (1997)

6. Wu, N.Q.: An Approach to Partner Selection in Agile Manufacturing. Journal of Intelligent Manufacturing 10, 519-529 (1999)

7. Ma, P.J.: Study on Partner-Selecting Strategy in Agile Manufacturing. China Mechnical Engineer 10, 1176-1179 (1999)

8. Fang, Y.D.: Research of Manufacturing Resources Optimum Allocation Technology Supporting Rapid Extended Manufacturing. Northwestern Polytechnical University Philosophy Doctor Dissertation (2005)

9. Wang, S.R.: Research of Ant Colony Algorithm Optimization Theory Model and Job-shop Application. ZheJiang University Press, ZheJiang (2003)

10. Li, S.Y.: Ant Colony Algorithm and Application. Haerbing Technology Press, Haerbing (2004)

11. Fang, Y.D.: Research and Realization of Partner Selection System in Cooperative Manufacturing Based on Web. System engineer 23, 118-123 (2005)

12. Wen, Z.: The discussion about problems for grey relation theory. Data Stat. and management 18, 25-29 (1999)

13. Yang, D.: Research of Ant Colony Algorithm Applied in the Combination Optimization. Tianjing University Press, Tianjing (2004) 